\title{
Real-time mobile EFTPOS: challenges and implications of a world first application
}

\author{
S.R. Elliot \\ School of Information Systems \\ The University of NSW, Sydney 2052, Australia \\ Telephone [+612] $3854736, \quad$ Fax [+612] 6614062 \\ Email_s.elliot@unsw.edu.au
}

\begin{abstract}
This paper describes the world's first implementation of real-time mobile electronic funds transfer at point of sale (EFTPOS). Keys to the success of this application were: business enthusiasm creating demand-pull; a mobile data packet switching service providing technology-push; an industry and community ready for change; a determined systems integrator; and a small independent taxi co-operative with a record of innovation which was seeking to address its business problems. These problems included cash flow difficulties for owners and zero population growth in its core geographical market. The major benefit sought by the taxi company was an expansion in its non-cash market to include EFTPOS card holders - an expected \$1 million in new business in the first full financial year. The implications of this application are likely to be of major significance for other industries and in other countries.
\end{abstract}

\section{Keywords}

Strategic IS, telecommunications technologies, technological innovation, distributed systems, banking, transportation

\section{INTRODUCTION}

The world's first implementation of real-time mobile electronic funds transfer at point of sale (EFTPOS) occured in Sydney, Australia late in 1994. A small taxi co-operative, with less than $5 \%$ of a market dominated by a major competitor and facing zero population growth in its core geographical market, sought to expand its market by direct appeal to customers in the community wanting to use non-cash means of payment. The taxi co-operative provided the initial application, however, it was only one of seven major players necessary to implement mobile EFTPOS. This paper describes the motivations and challenges faced by the different firms; considers how the system 
operates and the components and protocols necessary to support its operation; looks at the outcomes; and reviews the likely implications of this application for other industries and for other countries.

\section{THE INDUSTRY}

Each year in Australia an estimated 400 million taxi passenger journeys are taken generating a total revenue of more than $\$ 2$ billion. The industry provides regular employment for 50000 drivers and support staff and is made up of some 10000 small businesses which are mostly organised into co-operatives. The purpose of the cooperatives is to share costs and provide services, particularly the establishment and operation of a radio call service. Apart from a major role in the local public transport industry, taxis play a important part of the tourism industry. Australia has more than 15000 taxis with some 4800 located in Sydney. (source: Cabcharge).

Payment of taxi fares is primarily cash-based, although non-cash payment means are increasing in importance. Owned by major taxi groups, Cabcharge Australia P/L was formed in 1976 to provide account services to customers. Today, some $85 \%$ of the nation's taxis utilise Cabcharge. The Cabcharge system also accepts third party credit cards (including American Express and Diners Club) which do not require authorisation of individual transactions. Cabcharge supports its operations through a $10 \%$ service fee on each transaction. In the last financial year, Cabcharge's turnover exceeded $\$ 275$ million. The taxi industry has for some years, however, recognised the need for an updated non-cash payment system. Many large customers became dissatisfied with paying Cabcharge the $10 \%$ surcharge since it could amount to hundreds of thousands of dollars for each customer each year. Drivers and owners were unhappy since they had to wait 5-6 weeks for payment of account fares. The Cabcharge dockets also did not reflect the growing community demand for EFTPOS as a means of payment.

Australia has one of the world's highest levels of EFTPOS use. Since its introduction in 1985, some 12.7 million EFTPOS cards are now being used by the population of 18 million. EFTPOS is used in Australia differently from other countries. Internationally, EFTPOS is predominantly a means of processing credit transactions whereas debit transactions (ie access to a customer's own funds) have proven to be more popular in Australia. The taxi industry was, therefore, in a position where community demand for new payment mechanisms had not been reflected by the industry's offerings. Taxis were not catering for a potential market of customers wanting to pay their fare by EFTPOS, using a debit card. This situation appeared, to several firms, to be an unrealised business opportunity.

This application is characterised by the large number of major players involved: the taxi co-operative (Manly Warringah Cabs - MWC); the telecommunications service provider (Telstra); the manufacturers (Ingenico and Motorola); the EFTPOS switch (MasterCard); the bank (Commonwealth Bank of Australia - CBA); and the systems integrator, Mobile EFT Technologies - MET. The number of major players required 
was related more to the complexity of the application than the degree of complexity in the technology.

Not surprisingly, business motivations varied. The motivation for the two person systems integration firm, MET, was a commitment to the vision of mobile EFTPOS and a determination to make it work. The acquiring bank, CBA, sought to promote card use and a new business area. MasterCard sought to increase the acceptance of its debit cards. Telstra, facing a recently de-regulated telecommunications marketplace, looked to establish itself in a new market area, and the manufacturers, Motorola and Ingenico, sought future hardware sales.

The initial impetus for EFTPOS by MWC, the taxi co-operative, was to address driver dissatisfaction and to improve owner cash flow. This position quickly moved to an appreciation of business opportunities to attract customers in the existing market and to acquire a new market segment. Existing corporate customers were attracted by the potential to reduce the $10 \%$ levy charged by Cabcharge. The new market segment was non-cash, non-corporate customers. Recognising the irresistible movement towards use of credit and debit cards by the community, EFTPOS in taxis could attract more casual customers. Of secondary importance was the tourist market which should grow in the leadup to Sydney's Olympics Games in 2000. Electronic payments with international cards were considered to be increasingly significant in this future.

The challenges, both technical and managerial, were not insignificant although perhaps the biggest challenge was to get all seven major players working together to a common schedule. Telstra's technical challenge was to provide wireline performance within a wireless link. Motorola and Ingenico worked jointly to develop reliable EFTPOS application software on an integrated mobile terminal device experiencing variable power supply. MET specified the terminal device software and hardware, tested and implemented the systems, trained users and generally drove implementation at an operational level. MWC, as a co-operative, needed to convince its taxi owners to spend $\$ 2500$ for each taxi system - a not insignificant barrier to entry for the co-operative's 225 taxis. CBA established a pathway for mobile EFTPOS transactions into the local and international banking system, certified the wireless terminal device and developed settlement systems. MasterCard's major challenges were in project management of the parties.

First implemented in December 1994, the operation of mobile EFTPOS in taxis appears identical to EFTPOS use in stationary outlets. The operator (ie the taxi driver) places a debit or credit card in the EFTPOS handset card reader and the customer enters a Personal Identification Number and the amount. Instead of transmitting the transaction by land-line, the mobile EFTPOS transaction request is transmitted via radio and public data network to MasterCard's Australian Processing Centre (APC). Subsequently, the request is treated as any other EFTPOS transaction to be switched to the customer's bank and account, as shown in Figure 1. Advice of approval or denial is returned by the bank to the APC switch and thence back to the taxi. Average message response times are 3-4 seconds for local banks and 6-10 seconds for banks located overseas. 


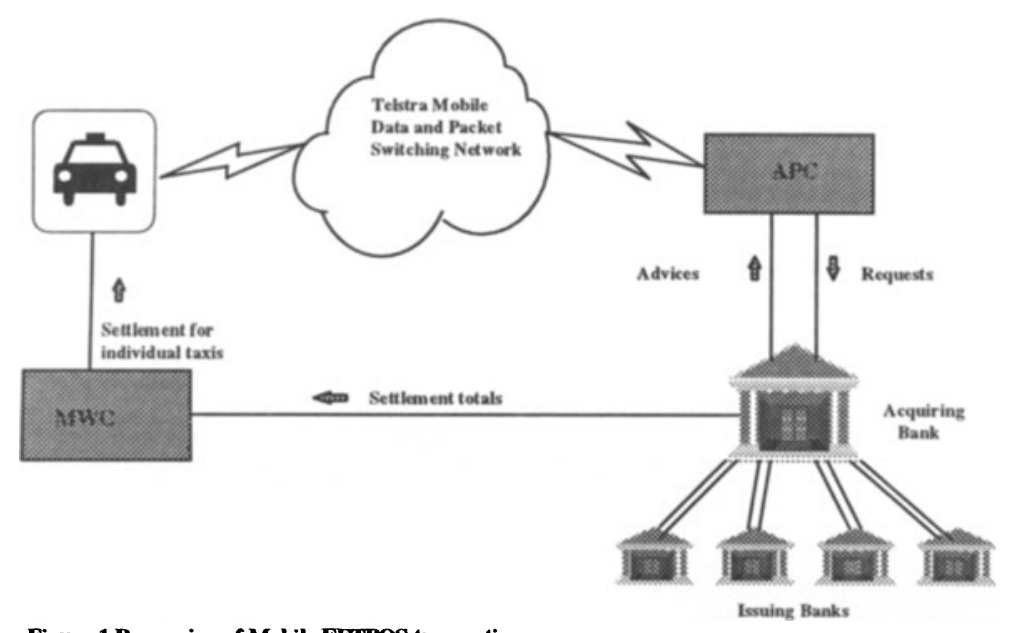

Figure 1 Processing of Mobile EFTPOS transactions.

Settlement with taxi owners is different from other EFTPOS arrangements, although this is not due to the mobility of the application. The taxi company, MWC, is a co-operative of taxi owners rather than a single merchant. The customer's bank (ie the card issuing bank) advises the acquiring bank of transactions to affect settlement with the taxi owners. The acquirer (here the CBA) provides details of transactions to the taxi company. The taxi company separates and amalgamates transactions to individual taxi owners and returns a file of direct credit transactions. Payment is made into taxi owner's accounts within three days of the original transaction. Settlement for a day's EFTPOS transactions is made by the Commonwealth Bank to MWC overnight. This settlement is the source of funding for MWC's direct payment to owners / drivers. In return for this rapid payment system the taxi owners / driver receive only $98 \%$ of the fare.

\section{PRIMARY COMPONENTS}

The wireless terminal device comprises a secure EFTPOS handset and radio modem. The EFTPOS handset selected is an Ingenico PX318 pinpad similar to those used by major retail chains. Use of an established EFTPOS handset assisted in implementation and contributed to customer acceptance. Magnetic cards are read in a dip style rather than by a swipe reader as the dip style allows for the future implementation of contact Smart card technology. The PX318 has a memory capacity of $256 \mathrm{~KB}$, sufficient to enable concurrent processing of credit, debit and Smart card applications. The PX pinpad is a secure processor in which all programs, data and internal data transfers are encrypted based on a 64 bit Data Encryption Standard (DES) key. A small impact printer produces a duplicate receipt. 


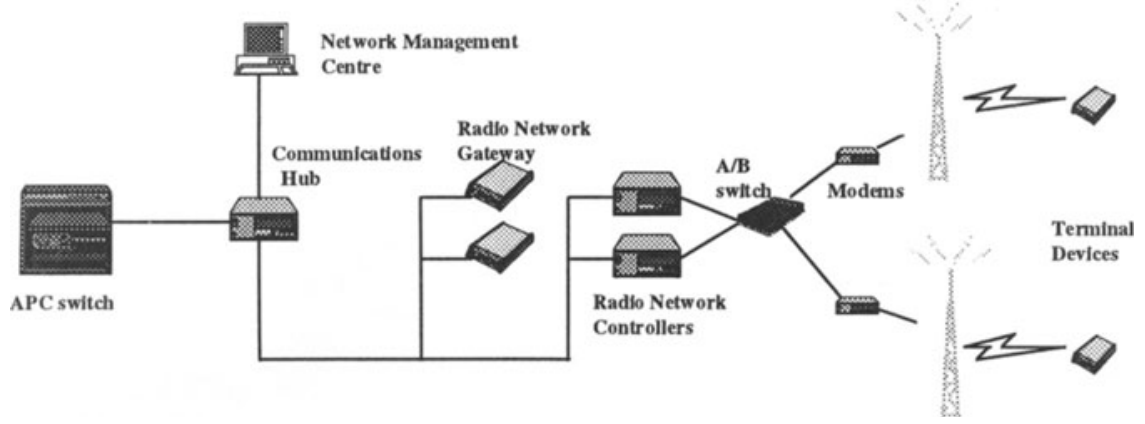

Figure 2 Radio Data Network.

The radio modem is Motorola's RM405i transmitting at $800 \mathrm{MHz}$ with a raw data rate of $19.2 \mathrm{kbs}$. Located in a small junction box which also houses a power supply adaption circuit connected to the car electronics, the radio modem is connected to the handset and a roof mounted aerial. The power source is the vehicle's 12 volt battery. Substantial software development was necessary for both handset and modem to support this EFTPOS application.

The radio data network infrastructure, Telstra's MobileData service, is based on Motorola's DataTAC 5000 system. As can be seen in Figure 2, the major components of the infrastructure are: radio towers (forming a cellular data network); a radio network gateway (converting protocols, authorising all service access on the network and registering each wireless terminal device); radio network controllers (routing messages between the gateway and wireless terminal devices over particular radio towers); a communications hub (providing protocol conversion between the DataTAC system and the host); and a network management centre (supporting system management functions). Communications between the radio network and MasterCard's APC are via a public data packet switched service. Capacity of the Telstra MobileData service is rated at 100,000 packets per hour.

The component responsible for the biggest operational problem has been the vehicle's power source. Taxis are prone to battery failure since the high daily mileage means that batteries boil most days and last for only a few months. When the car battery is flat the call service radio and EFTPOS are both inoperable, although this is not the worst problem. A failing battery is unable to produce a reliable current. In these circumstances the terminal device may inexplicably cease to function. The EFTPOS handset and radio modem have required modification to operate reliably at a range of currents due to varying battery states. The handsets and radio modems have proven to be very robust despite the additional vibration involved in being mobile. Printers are the biggest day to day headache. Experience has shown that cheap paper does not produce an acceptable copy. Telecommunications black spots due to Sydney's high rise buildings and hilly terrain have also posed a problem, which has been addressed by Telstra installing additional radio towers to improve radio area coverage. 
Alternative systems, including analogue radio and analogue and digital telephony were considered but found wanting. The first thought was to utilise the existing radio network for the taxi call service which is based on analogue radio technology. This operates at a slow $12 \mathrm{MHz}$; has little or no security; and proved to be unreliable for a data transfer service due to radio blackspots and to the volume of radio traffic in peak times. Several companies looked at ways to support mobile EFTPOS services based on use of the mobile GSM digital telephone adapted for EFTPOS transactions. Each online transaction would require a call to the authorising body (ie the card issuer) and another call to approve the transaction. Two calls became an expensive component in a small value transaction and the time to establish two calls was excessive. Off-line transactions (ie accumulated in the taxi during the day and transferred by fixed telephone line to the bank each night) were considered but could not adequately support debit payments .

\section{$6 \quad$ PROTOCOLS}

At the time of implementation, the only radio frequency transmission protocols available were proprietary standards from major equipment suppliers. Telstra avoided potential incompatability problems by selecting the latest protocol set from a major supplier and building their service capability based exclusively on Motorola's DataTAC 5000 system. As can be seen in Figure 2, communications from the host to the Motorola DataTAC system are via a public data network X.25 protocol, which maps to the ISO Reference Model's physical, data link and network layers. Motorola's Radio Network Gateway 5000 protocol maps to transport, session, presentation and application layers.

Motorola's Standard Context Routing protocol supports communication from the host to a number of terminal devices using a single logical X.25 connection. Communications between the various DataTAC internal system components rely on Ethernet, RS-232, HDLC and TCP/IP. Motorola's Native Control Language protocol maps to physical, data link and presentation layers for both the EFTPOS handset and the radio packet modem. Wireless transmissions are supported by Motorola's RD-LAP open protocol, which enables multiple concurrent use of the medium with collision detection, contention and retries.

EFTPOS transactions comply with Australian Standard 2805 which is consistent with the requirements of major local and international debit and credit card owning organisations. All EFTPOS transactions, mobile and stationary, require encryption to the international 64 bit Data Encryption Standard.

\section{OUTCOMES}

Twelve months after implementation, MWC's anticipated benefits of $\$ 1$ million in new business in the first full financial year appear conservative. Account work has increased more than $50 \%$ with EFTPOS transactions being responsible for the majority of the increase. MWC's owners and drivers have responded favourably to the increased business and rapid settlement of non-cash business. Mobile EFTPOS has proven to be rewarding for MasterCard and financial institutions and to be of no greater risk than for non-mobile EFTPOS transactions. Hardware sales have increased rapidly for both 
Ingenico and Motorola and Telstra is seen to provide the nation's most utilised mobile data service.

Nine months after implementation, however, Cabcharge responded with the launch of pilot implementations of rival EFTPOS and stored value card products. The stored value card has been targetted at a broader market being designed for use in trains and buses as well as cabs. This smartcard has not been widely released. Its distribution has been complicated by the international piloting of other, incompatible, smartcard products in Australia by MasterCard and Visa. Cabcharge's EFTPOS system currently processes only credit cards and retains the $10 \%$ service fee. There is certain to be contention in the taxi industry while these non-cash payment issues are being resolved.

\section{IMPLICATIONS}

Many applications of real-time mobile computing have been in specialised and support functions, such as co-ordination of equipment servicing or price checking by sales staff, rather than in mainstream business. This application of mobile computing addresses a core business activity in an international industry. It demonstrates integration of stationary and mobile processors in a time critical mainstream business application and performs reliably and consistently in this role. Initial implications for senior management in other industries are that mobile computing must be considered for core business activities. First and other early adopters of mobile EFTPOS are achieving competitive benefits which will be regarded with interest not only by the taxi industries world-wide but by any local or international industry seeking a transportable, relocatable and flexible non-cash payment system. The existing system could be implemented with little modification in other mobile industries such as couriers and truckers.

Now that the nexus between EFTPOS and a fixed location has been broken new applications abound. The system could be developed further to produce an attache casesized device complete with 12 volt battery to provide transportable EFTPOS. As much small business is conducted away from fixed premises (eg market stall holders, home gardeners, lawn mowing companies, electricians, plumbers etc) a transportable EFTPOS system could prove a desirable payment system.

The application of most interest, however, is internationally - particularly in Asia. Many Asian countries experience poor communications by land line and unreliable power sources and so cannot adequately support the electronic payment systems necessary for their international tourism industries. The flexibility of mobile EFTPOS is such that a radio data network could be implemented at low cost and a reliable EFTPOS / ATM system made operational within a matter of weeks. A pilot implementation of such a system has already been undertaken.

Further implications of this case are for IS researchers, initially in the development of theory in first adoption of IT. The market leader (totally dominant in the provision of non-cash payment systems to the industry) was aware of the gap between the payment systems provided by the industry and changing community demand. This firm had researched the problem over a period of several years, selected a stored value card solution and had piloted a product. Nonetheless, their planning procedures appear to 
have taken too long; their stored value card solution did not comply with the standard adopted by the international leaders in the stored value card industry (Eurocard, MasterCard and Visa); and the company appeared to have been caught unaware by the implementation of mobile EFTPOS. Their response, after nine months, consisted of a rival mobile EFTPOS system which retained the $10 \%$ surcharge. There appears to be uncertainty at present as to widespread release of the stored value product.

Finally, the case provides significant insights into the mixed motivations present in consortia seeking co-operative advantage and to the empirical realities of strategic IS planning for inter-organisational systems. The innovative forces present in the different firms demonstrate the requirements for integration of innovations research and intentions-based models of IS adoption and diffusion. Neither of these theoretical areas, in isolation, provides a complete explanation of the circumstances resulting in this world's first application of IT.

The contribution of the many who willingly assisted in this project is gratefully acknowledged.

\section{REFERENCES}

Australian Payment Systems Council, (1995) Annual Report 1994/95. Reserve Bank of Australia, Sydney.

Cabcharge Australia, (1995) Corporate Report.

Kermode R.L., (1995) "Electronic payment system in taxis". Taxi. NSW Taxi Council July-August. Vol. 40, Nr. 6, pp 17-21.

Manly Warringah Cabs Co-operative Society Limited, (1994) Chairman's Report, Papers of the Annual General Meeting.

Manly Warringah Cabs Co-operative Society Limited, (1995) Chairman's Report, Papers of the Annual General Meeting.

Motorola, (1994) DataTAC 5000 System - Host Application Programmer's Guide. Motorola Canada. Richmond BC Canada.

Motorola, (1994) DataTAC Open Protocol Specification - Native Control Language Release 1.2. Motorola Canada. Richmond BC Canada.

Motorola, (1995) Personal Messenger 100D: Two-Way Wireless Modem Card Application Developer's Guide. Motorola Inc. Bothell WA. USA.

NSW Department of Transport, (1995) Annual Report 1994/1995. Sydney.

Yin R.K., (1994) Case Study Research: Design and Methods, 2nd Ed. Sage Publications Inc. Thousand Oaks Calif. 
and various technical, publicity and strategic planning details from Cabcharge, Ingenico, Manly Warringah Cabs, MasterCard, MET, Motorola and Telstra,

\section{BIOGRAPHY}

Since commencing in the computer industry in 1972 Steve Elliot has worked in Australia, Europe and Asia in business, government, education and with the United Nations. He is currently Director of the Information Technology Research Centre at the University of New South Wales in Sydney. Steve has degrees in Economics and Information Systems from University of Sydney and University of Technology, Sydney and a $\mathrm{PhD}$ in strategic IS planning from University of Warwick, UK. His major research interest lies in the strategic use and management of IS, particularly telecommunicationsbased IS. 